\title{
OE7.2 Novel Millimeter-Wave Electro-optic Modulator
}

\author{
William B. Bridges, Finbar T. Sheehy \\ California Institute of Technology, Pasadena, California, U.S.A. \\ James H. Schaffner \\ Hughes Research Laboratories, Malibu, California, U.S.A.
}

A waveguide $\mathrm{LiNbO}_{3}$ electro-optic modulator has been demonstrated with a novel wave-coupling technique which greatly reduces phase-velocity mismatch. An $8-12 \mathrm{GHz}$ version produces $48^{\circ}$ phase modulation with $126 \mathrm{~mW}$ of drive power. A $60 \mathrm{GHz}$ version is being built.
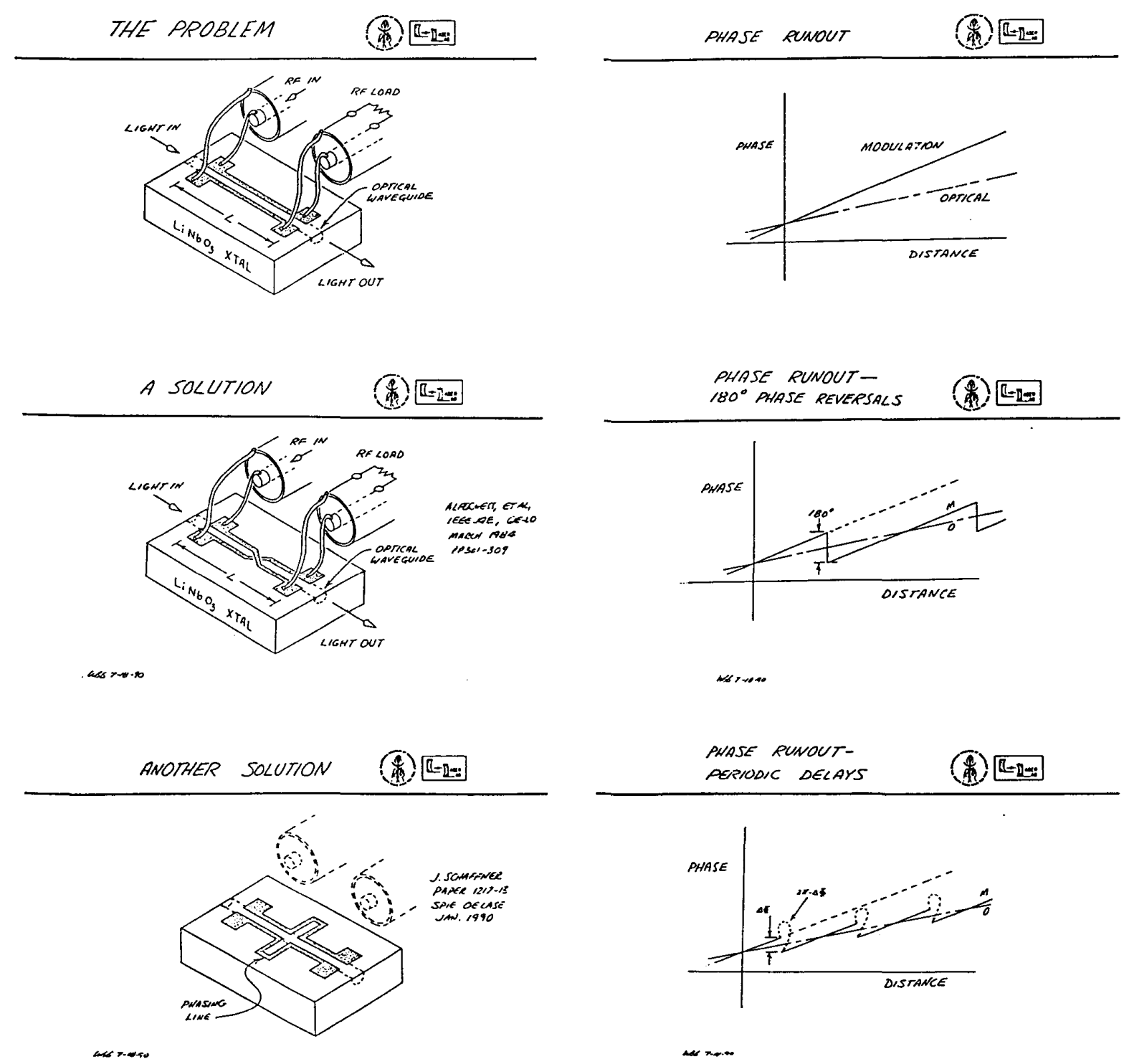

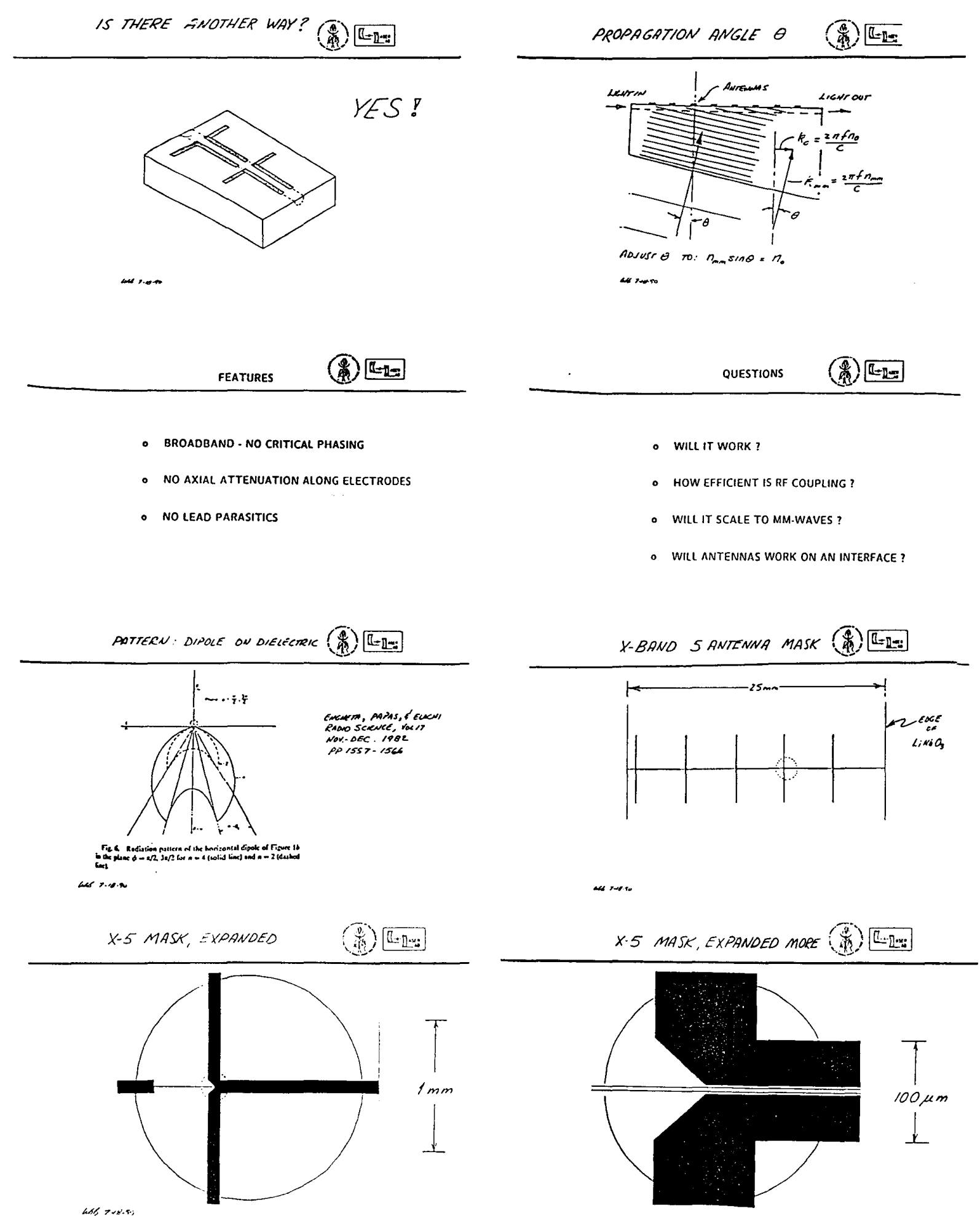

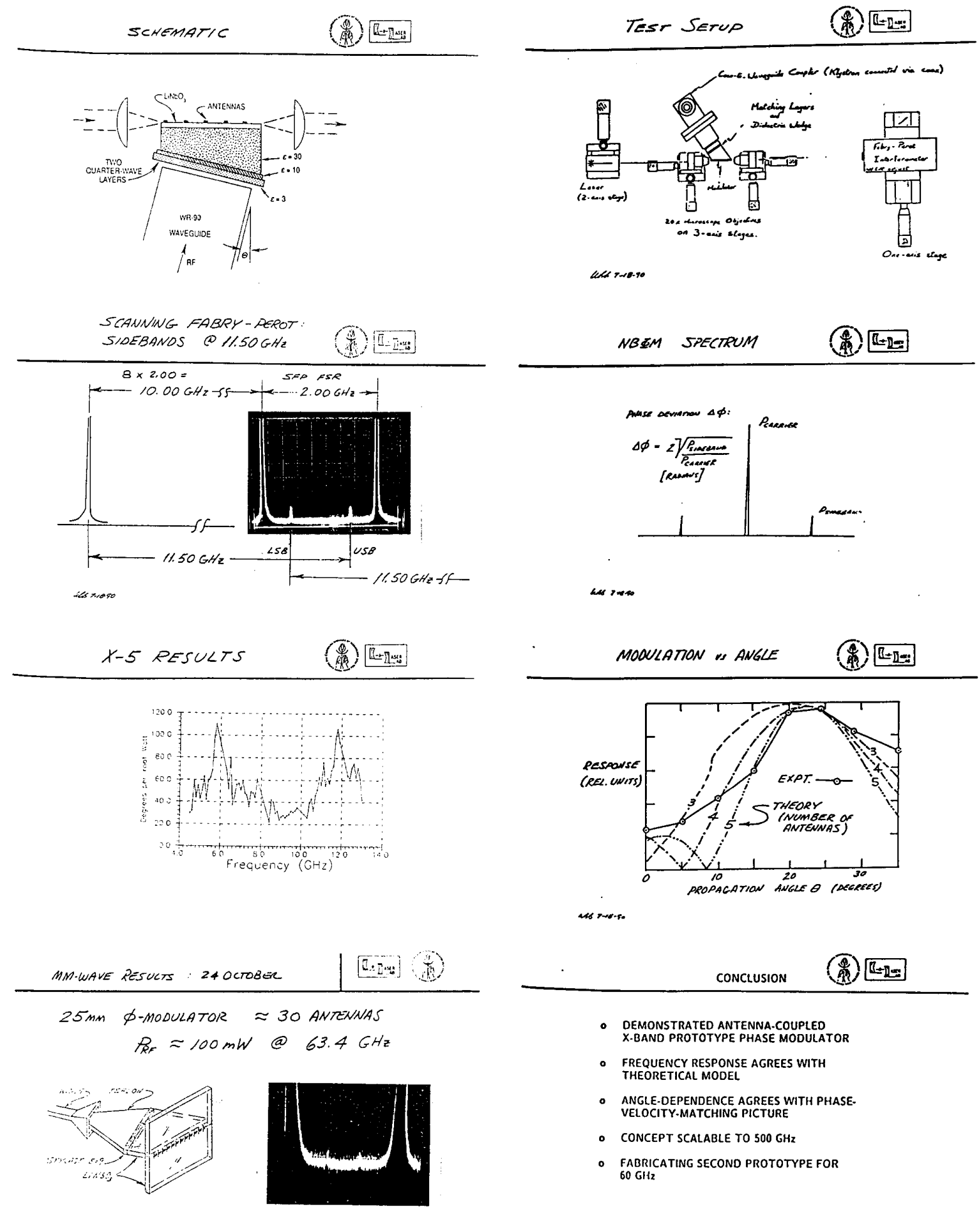